\title{
Effectiveness and adverse effects of hormonal therapy for prostate cancer: Japanese experience and perspective
}

\begin{abstract}
Mikio Namiki ${ }^{1}$, Satoru Ueno ${ }^{1}$, Yasuhide Kitagawa ${ }^{1}$, Takashi Fukagai ${ }^{2}$ and Hideyuki Akaza ${ }^{3}$
Recently, novel anti-androgens and inhibitors of androgen biosynthesis have been developed through the elucidation of mechanisms of castration resistance of prostate cancer. We believe that these new developments will improve hormonal therapy. On the other hand, there has been an increase in criticism of hormonal therapy, because hormonal therapy is supposed to induce adverse effects such as cardiovascular disease. In this review, we have introduced the Japanese experience of hormonal therapy, because we believe that there may be ethnic differences between Caucasians and Asian people in the efficacy and adverse effects of hormonal therapy. First, we showed that primary hormonal therapy can achieve long-term control of localized prostate cancer in some cases and that quality of life of patients receiving hormonal therapy is rather better than previously thought. Neoadjuvant and adjuvant hormonal therapy in cases undergoing radical prostatectomy or radiotherapy are very useful for high-risk or locally advanced prostate cancer. Further clinical trials are required to confirm the efficacy of neoadjuvant or adjuvant hormonal therapy. We showed that the death from cardiovascular diseases in Japanese patients receiving hormonal therapy was not higher than that in the general population. However, efforts should be made to decrease the adverse effects of hormonal therapy, because life-style change may increase the susceptibility to adverse effects by hormonal therapy even in Japan. Managements of endocrine and metabolic dysfunction, such as diabetes mellitus, are essential. New hormonal compounds such as selective androgen receptor modulators capable of specifically targeting prostate cancer are expected to be developed.
\end{abstract}

Asian Journal of Andrology (2012) 14, 451-457; doi:10.1038/aja.2011.121; published online 26 March 2012

Keywords: adverse effects; androgen deprivation therapy; hormonal therapy; prostate cancer

\section{INTRODUCTION}

Hormonal therapy has played an important role in the treatment of prostate cancer, since it was first introduced about 70 years ago by Huggins and Hodges. ${ }^{1}$ At present, hormonal therapy is still used as the first choice of treatment for advanced prostate cancer. It is frequently used as neoadjuvant or adjuvant therapy in cases undergoing radical prostatectomy or radiotherapy. Furthermore, hormonal therapy is sometimes the primary treatment for localized prostate cancer, especially in aged patients. Although widely used, hormonal therapy has recently been the subject of criticism. Some authors have reported that its effectiveness is minimal, ${ }^{2}$ while others suggested that it may reduce patients' quality of life (Qol) and induce adverse effects. ${ }^{3,4}$ Such reports should be evaluated very carefully. Accurate evaluation of the efficacy of primary hormonal therapy is very difficult, because many factors, such as the type of hormonal therapy used (i.e., castration alone, antiandrogen therapy or combined androgen blockade $(\mathrm{CAB})$ ) and the duration of hormonal therapy, affect the outcome of treatment.

In this review, we introduce Japanese experience of hormonal therapy for prostate cancer.

\section{EFFICACY OF PRIMARY HORMONAL THERAPY FOR LOCALIZED OR LOW-RISK PROSTATE CANCER}

Hormonal therapy is not recommended as the primary treatment for localized prostate cancer according to representative guidelines, such as the National Comprehensive Cancer Network guidelines. However, according to the Japanese cancer registration statistics, many patients with localized prostate cancer have actually been treated with primary hormonal therapy. ${ }^{5}$ Despite urologist's explanation regarding the various treatments for localized prostate cancer, many patients select primary hormonal therapy. ${ }^{6}$ It is likely that many patients with localized prostate cancer select primary hormonal therapy, because medical treatment, such as primary hormonal therapy, is more acceptable than more invasive treatments, such as surgery, for many Japanese patients. In addition, urologists themselves may also influence patients' decisions, because they have experience of the effectiveness of primary hormonal therapy.

The ethnic background of patients may play an important role in the effectiveness of hormonal therapy and in susceptibility to adverse effects. The efficacy of hormonal therapy has been compared between Japanese Americans and Caucasians living in Hawaii. ${ }^{7}$ Both groups had similar backgrounds, but both overall and cause-specific survival rates of Japanese Americans were better than those of Caucasian subjects (Figure 1). The overall survival rate was also compared among Caucasian, Chinese and Filipino patients living in Hawaii. The Chinese subjects showed similar trends to Japanese patients. Therefore, sensitivity of prostate cancer to hormonal therapy and susceptibility to adverse effects may differ among ethnic groups.

${ }^{1}$ Department of Integrative Cancer Therapy and Urology, Kanazawa University Graduate School of Medical Science, Kanazawa 920-8640, Japan; ${ }^{2}$ Department of Urology, Showa University School of Medicine, Tokyo 142-8666, Japan and ${ }^{3}$ Research Center for Advanced Science and Technology, University of Tokyo, Tokyo 153-8903, Japan Correspondence: Professor M Namiki (namiki1@kenroku.kanazawa-u.ac.jp)

Received: 15 July 2011; Revised: 27 September 2011; Accepted: 30 September 2011; Published online: 26 March 2012 
Log-rank test $P=0.001$

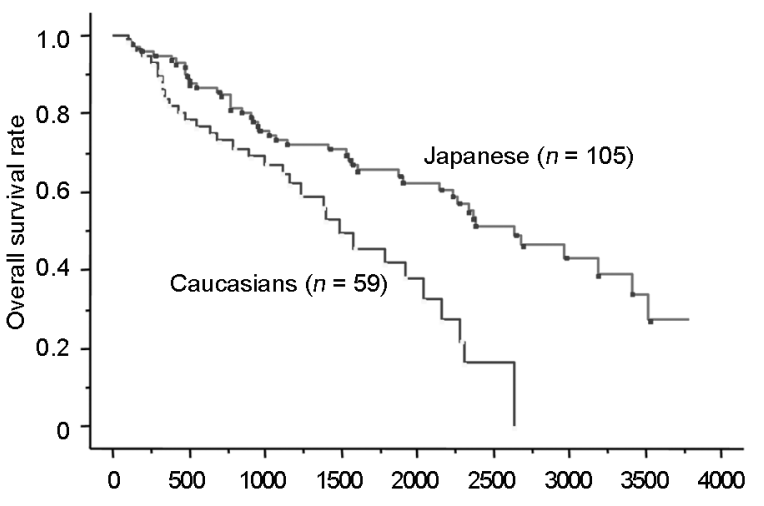

Log-rank test $P=0.036$

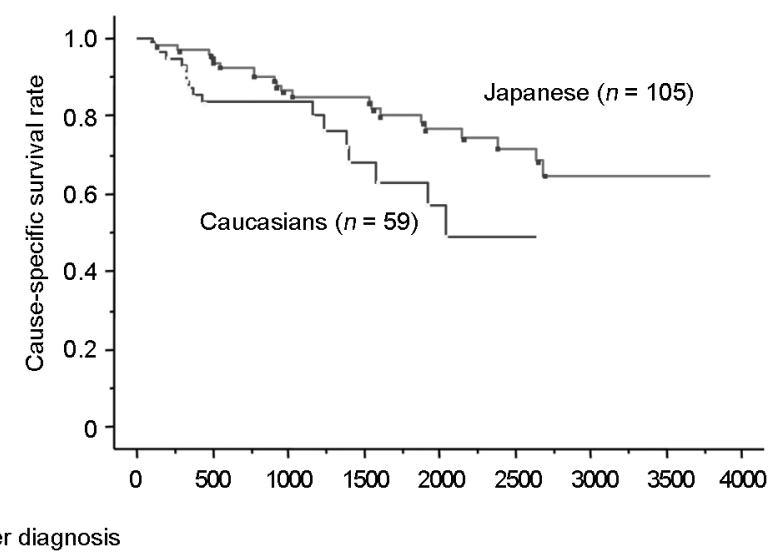

Figure 1 Comparison of the efficacy of hormonal therapy between Japanese American and Caucasians living in Hawaii (modified from Ref. 7).

Akaza et al. ${ }^{8}$ reported that overall survival rate of patients with localized or locally advanced prostate cancer treated with primary hormonal therapy was equivalent to life expectancy of age-matched subjects in the healthy population. Before Akaza's report, Egawa et al. ${ }^{9}$ had already reported that primary hormonal therapy was as effective as radical prostatectomy with regard to disease-specific survival rate in localized prostate cancer. In their report, disease-specific survival rate at 10 years of 56 patients with well-differentiated prostate cancer treated with primary hormonal therapy was $100 \%$. Why is the outcome of primary hormonal therapy so excellent, especially in welldifferentiated prostate cancer? Kitagawa et al. ${ }^{10}$ analyzed the histological effects of hormonal therapy in specimens from patients treated with radical prostatectomy after neoadjuvant hormonal therapy. They reported that histologically cured or nearly cured patients accounted for more than $40 \%$ of the total number. In addition, the recurrencefree survival rate of the patients with histologically complete apoptosis was $100 \%$. These results suggest that some cases of localized prostate cancer could be cured by primary hormonal therapy alone. Schulman et al. ${ }^{11}$ also performed neoadjuvant hormonal treatment for 3 months before radical prostatectomy in patients with localized prostate cancer, and reported good histological effects. Labrie et al. ${ }^{12}$ also reported that about $80 \%$ of stage B prostate cancer could be controlled for long-term with primary hormonal therapy.

These reports raise questions about which groups of patients would be good candidates for primary hormonal therapy. We performed a retrospective review of the efficacy of primary hormonal therapy in 628 patients with localized or locally advanced prostate cancer treated with primary hormonal therapy at seven institutions in Japan, and attempted to predict patients in whom the disease could be controlled for long periods by primary hormonal therapy. ${ }^{13}$ Disease-specific and overall survival rates at 8 years in all patients were $89.1 \%$ and $75.0 \%$, respectively. In addition, disease-specific survival rate at 8 years of patients given $\mathrm{CAB}$ treatment was $95.3 \%$, which was significantly higher than that of patients treated with castration alone. We classified the patients into three risk groups based on pre-treatment prostate-specific antigen (PSA) level and Gleason score according to a modification of the D'Amico risk grouping. ${ }^{14}$ Disease-specific survival rates at 8 years of low-, intermediate- and high-risk groups were 97.6\%, 95.4\% and $78.3 \%$, respectively (Figure 2). Next, we divided low- and intermediaterisk patients into two groups with PSA level $<0.2 \mathrm{ng} \mathrm{ml}^{-1}$ after hormonal therapy. The time to PSA level $<0.2 \mathrm{ng} \mathrm{ml}^{-1}$ was within
6 months in 192 patients (good response group, group G). These patients accounted for $30.6 \%$ of the total patient population. We classified the 139 patients whose PSA level did $\geqslant 0.2 \mathrm{ng} \mathrm{ml}^{-1}$ within 6 months as the poor response group (group P). The disease-specific survival rates at 8 years of groups $\mathrm{G}$ and $\mathrm{P}$ were $98.9 \%$ and $94.0 \%$, respectively. Notably, there were no cancer-related deaths during the observation period among the 133 patients in group $G$ receiving $C A B$ treatment in this study. Although a randomized controlled trial may be necessary for utilization of primary hormonal therapy in patients in whom such treatment is considered more effective, based on the results of our study T1c-T3 patients with PSA level $\leqslant 20 \mathrm{ng} \mathrm{ml}^{-1}$ and Gleason score $\leqslant 7$ may be good candidates for the initial hormonal therapy. These patients accounted for $52.7 \%$ of the total number of T1c-T3 patients in our study. Hormonal therapy may be suitable as the initial treatment in such patients, but changing to another curative regimen or combination therapy with radiotherapy or radical prostatectomy should be considered, if the PSA value does not decrease to $<0.2 \mathrm{ng} \mathrm{ml}^{-1}$ after 6 months of hormonal therapy. However, in patients whose PSA value drops to $<0.2 \mathrm{ng} \mathrm{ml}^{-1}$ within 6 months of the commencement of hormonal therapy, continuation of the same regimen may be reasonable with careful observation (Figure 3).

Another preference for early-stage prostate cancer patients involves active surveillance. No study in PSA screened low-risk cancer has ever found that treatment is better than no treatment. Therefore, further investigations are necessary to compare the disease-specific or

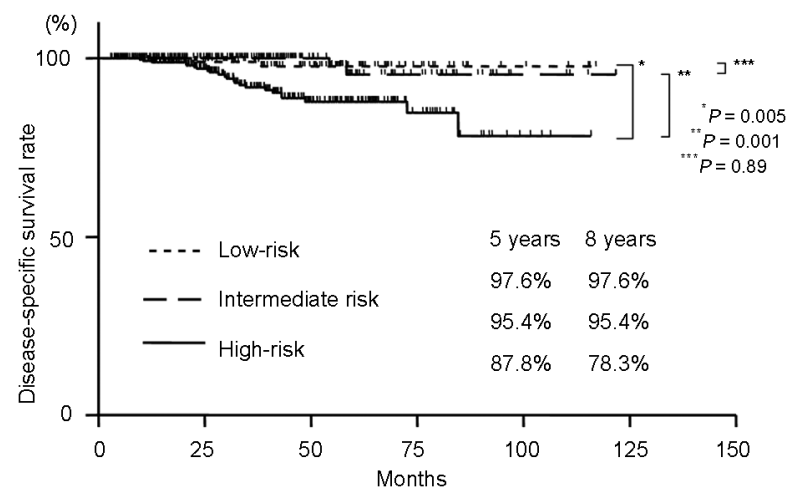

Figure 2 Disease-specific survival rates of low-, intermediate- and high-risk groups treated with primary androgen deprivation therapy (cited from Ref. 13). 


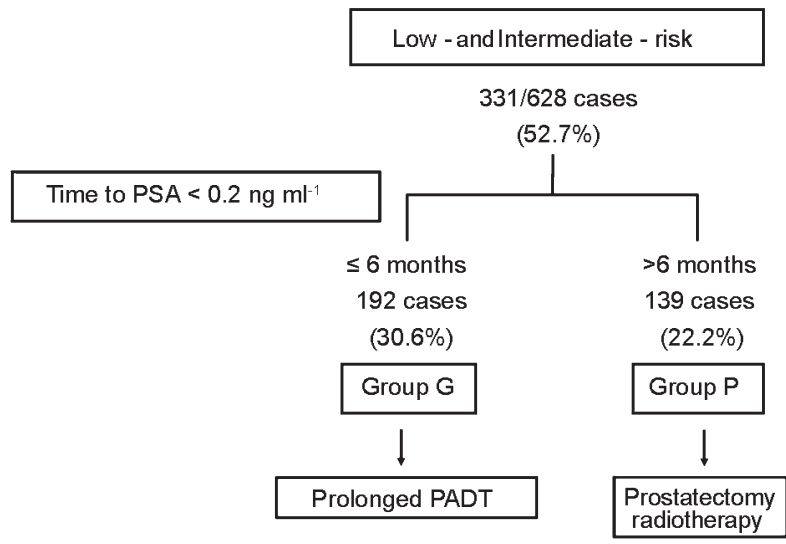

Figure 3 Treatment algorithm for patients with low- and intermediate-risk localized prostate cancer (cited from Ref. 13). PADT, primary androgen deprivation therapy; PSA, prostate-specific antigen. Group G: good response group; Group P: poor response group.

progression-free survival rates of a low-risk group, such as group G, with those of active surveillance group. The prostate cancer intervention versus observation trial has recently shown that radical prostatectomy did not reduce mortality any more than observation in men with low PSA or low-risk prostate cancer. However, even cancer cells for which observation alone without treatment was at first thought to be sufficient are not always inactive after long periods. These cancer cells may become impossible to be controled due to malignant transformation by gene mutation during follow-up. ${ }^{15}$ In addition, most patients are anxious about the status of their disease, and few are willing to rely solely on active surveillance. ${ }^{16}$ Another possible problem is the period over which hormonal therapy should be continued. Labrie et al. ${ }^{12}$ performed long-term hormonal therapy in stage $\mathrm{B}$ and $\mathrm{C}$ patients and discontinued the treatment in patients who did not show PSA recurrence. An increase in PSA occurred in only two of 33 patients with stage $B$ and $C$ prostate cancer who stopped treatment after continuous $\mathrm{CAB}$ for more than 6.5 years. In addition, seven of eight patients with localized prostate cancer who received $C A B$ treatment continuously for 6.5-9.0 years before stopping treatment, showed no PSA failure at least 5 years after cessation of CAB. CAB treatment was restarted in patients showing PSA recurrence after cessation of the initial hormonal treatment, and control was achieved again in most cases. Thus, it was concluded that CAB treatment for 7 years may be suitable in such cases. Recently, Tanaka et al. ${ }^{17}$ also investigated when hormonal therapy could be discontinued based on nadir PSA levels after commencement of treatment. They concluded that a relatively short period, e.g., 3 years, may be sufficient in cases in which the nadir PSA dropped to $<0.01 \mathrm{ng} \mathrm{ml}^{-1}$. Intermittent hormonal therapy was reported to be useful for the treatment of advanced prostate cancer to maintain sensitivity to androgens. ${ }^{18}$ However, care is required in application of this treatment to localized prostate cancer, because cancer that could be controlled over the long term or may be cured by appropriate hormonal therapy ${ }^{12}$ may progress to develop more malignant potential by incomplete androgen ablation.

According to the modified D'Amico classification reported previously, ${ }^{14}$ disease-specific and progression-free survival rates of the high-risk group treated with primary hormonal therapy at 5 years were $87.8 \%$ and $58.8 \%$, respectively. From these results, long-term control by primary hormonal therapy seems difficult in the high-risk group. However, Mizokami et al. ${ }^{19}$ reanalyzed the previous data and showed that the results for the high-risk group are not necessarily pessimistic in patients whose PSA values drop to $<0.2 \mathrm{ng} \mathrm{ml}^{-1}$. They proposed that high-risk prostate cancer patients should be first treated with neoadjuvant CAB. Then, once a PSA value of $<0.2 \mathrm{ng} \mathrm{ml}^{-1}$ has been reached, patients with favorable parameters (Gleason score $\leqslant 6$, pretreatment PSA $\leqslant 20 \mathrm{ng} \mathrm{ml}^{-1}$, time to PSA $<0.2 \mathrm{ng} \mathrm{ml}^{-1}$ within 6 months after the commencement of hormonal therapy) are likely to have less possibility $(<25 \%)$ of relapse at 10 years after commencement of CAB. Therefore, such patients could select any treatment option, e.g., surgery, radiotherapy or primary hormonal therapy. However, they recommended that poor responders to neoadjuvant $\mathrm{CAB}$ should be treated with more intensive therapy using $\mathrm{CAB}$ combined with high-dose rate brachytherapy, intensity-moderated radiotherapy or some forms of chemotherapy.

\section{ISSUES OF QOL AND MEDICAL COST}

Long-term hormonal therapy is sometimes criticized for reducing patients' QoL. In our institution, the QoL of prostate cancer patients treated with primary hormonal therapy was investigated using the Androgen Deficiency in Aging Male questionnaire to allow comparison with healthy aged men who visited the institution for medical examinations. Surprisingly, the QoL of men receiving primary hormonal therapy was rather better than that of the healthy controls, except for sexual function in men aged 50-59 years. ${ }^{19}$ Actually, most prostate cancer patients reported no anxiety regarding their primary disease or side effects of the treatment. Kato et al. ${ }^{20}$ evaluated healthrelated QoL in Japanese men receiving hormonal therapy for prostate cancer using SF-36 and University of California at Los Angeles Prostate Cancer Index. They concluded that general health-related QoL was mostly unaffected by hormonal therapy and that most patients did not report sexual bother despite deterioration of sexual function. These reports suggest that QoL of prostatic cancer patients receiving hormonal therapy is rather better than previously thought, at least in Japan.

Medical costs can also be a significant issue. The medical cost of hormonal therapy is higher than those of other treatments, but there are costs that are calculated directly, such as medical costs or transportation for hospital visits, and costs that cannot be calculated, such as loss of employment for disease treatment or psychological burden. Therefore, estimation of cost is very difficult, and further studies are required to compare costs with those of other types of treatment.

\section{ROLE OF HORMONAL THERAPY FOR HIGH-RISK OR LOCALLY ADVANCED LOCALIZED PROSTATE CANCER}

Patients with high-risk or locally advanced prostate cancer with high Gleason score, elevated PSA level and advanced clinical stage have a high probability of treatment failure after initial management by singletreatment modalities, such as hormonal therapy, ${ }^{21}$ radical prostatectomy, external beam radiation therapy (EBRT) or brachytherapy. ${ }^{22,23}$ Therefore, it is extremely important to establish the most effective treatment strategy for patients with high-risk prostate cancer. As high-risk patients may have locally advanced disease with direct extension and/or micrometastases, various combinations of treatments have been developed to augment cancer-specific survival. Neoadjuvant and/ or adjuvant hormonal therapy offer synergistic enhancement of radiation therapy or radical prostatectomy due to induction of apoptosis. Moreover, hormonal therapy may play a role in elimination of occult systemic disease. ${ }^{24,25}$ Whereas many studies have demonstrated benefits of hormonal therapy used in conjunction with EBRT to treat locally advanced prostate cancer, ${ }^{26-30}$ questions and criticisms remain, includ- 
ing the details of the duration, timing and contents of hormonal therapy. The results of radiation oncology group trial 9202 regarding effectiveness and adverse effects of hormone therapy are very informative. $^{31}$ These results suggest that cause-specific benefits of hormone therapy may have been offset by deaths from other causes induced by hormone therapy.

As the prolonged use of hormonal therapy results in increased incidence rates of adverse events, investigation of the optimal duration of hormonal therapy with maximization of clinical outcome and minimization of toxicity is a logical step in the management of localized high-risk prostate cancer. Further, we determine which patients with high-risk prostate cancer will actually benefit from hormonal therapy, even if there is some compromise in QoL associated with the adverse event profile of this treatment. Trials regarding adjuvant hormonal therapy have already demonstrated the superiority of longer periods of adjuvant hormonal therapy. ${ }^{29}$ Therefore, with sufficient care to prevent adverse effects due to hormonal therapy, better outcomes with further longer neoadjuvant hormonal therapy may be achieved. Trimodality treatment (EBRT+brachytherapy+hormonal therapy) has attracted attention as another method to produce better outcomes in cases of high-risk prostate cancer. ${ }^{32}$ According to the American Brachytherapy Society, brachytherapy alone is not recommended for high-risk prostate cancer, but can be used as a boost in conjunction with EBRT. ${ }^{33}$ In this multimodal approach, combined brachytherapy and EBRT theoretically delivers a possible escalated dose to the prostate and at the same time to extracapsular cancer extension. Although the American Brachytherapy Society provides no clear indications for neoadjuvant and/or adjuvant hormonal therapy with combination of brachytherapy and EBRT in high-risk prostate cancer, the duration of hormonal therapy could be reduced with such multimodality radiotherapy.

In contrast to the many efforts to develop better treatments for radiotherapy with hormonal therapy, there have been few clinical trials investigating the effectiveness of neoadjuvant or adjuvant hormonal therapy with radical prostatectomy. ${ }^{34}$ One reason for this is that early studies of neoadjuvant hormonal therapy did not confirm the improvement of overall survival despite improvements in the pathological findings. Another reason is that surgeons may have less interest in medical treatments, such as hormonal therapy. However, surgeons should consider the best methods of improving the results in cases of high-risk prostate cancer, because recent reports have indicated the superiority of radiotherapy for high-risk prostate cancer compared with radical prostatectomy. ${ }^{35}$ Recently Dorff et al. ${ }^{36}$ reported that 2 years of adjuvant androgen deprivation therapy (ADT) after radical prostatectomy resulted in an extremely low rate of disease recurrence and prostate cancer-specific death for high-risk patients in SWOG S9921 Study.

Finally, it should be stressed that it may be possible to eradicate high-risk or locally advanced prostate cancer with appropriate use of hormonal therapy in combination with radiotherapy or radical prostatectomy. Therefore, further well-designed clinical trials are required.

\section{ROLE OF HORMONAL THERAPY IN ADVANCED PROSTATE CANCER}

At present, hormonal therapy is still used as the primary treatment for advanced prostate cancer. However, the methods of hormonal therapy, castration alone, anti-androgen agents alone or CAB, are not necessarily the same. This makes the evaluation of hormonal therapy confusing. $\mathrm{CAB}$ consisting of $\mathrm{ADT}$ with luteinizing hormone-releasing hormone (LH-RH) analog and anti-androgen agents has replaced surgical castration and estrogen agents. In prostate cancer cells, dihydrotestosterone (DHT) is converted from testosterone produced in the testis. DHT which binds with androgen receptor (AR) in the nuclei of prostate cancer cells activates androgen-responsive genes, and finally plays a major role in the proliferation of prostate cancer cells. Androgen deprivation by $\mathrm{LH}-\mathrm{RH}$ analog or surgical castration induces apoptosis of prostate cancer cells, and the treatment effect for prostate cancer is put out clinically. On the other hand, testosterone and DHT are also converted from dehydroepiandrosterone and androstenedione secreted from the adrenal gland, and it has been reported that approximately $40 \%$ of androgen in prostate tissue is derived from the adrenal gland. ${ }^{37}$ Moreover, we showed that approximately $25 \%$ of testosterone in prostate cancer tissue remained after castration. ${ }^{38}$ These results suggested that ADT for prostate cancer requires not only surgical or medical castration using LH-RH analog, but also anti-androgen agents. Anti-androgen agents block the activities of androgens by various mechanisms. Therefore, it is possible that the different clinical outcomes of CAB treatment are due to the various kinds of anti-androgen agents used. ${ }^{39}$

Recently, the results of a phase 3 randomized controlled trial of CAB in advanced prostate cancer showed that LH-RH analog +80 -mg of bicalutamide was more effective than LH-RH analog alone, with favorable safety profiles and cost effectiveness and without deterioration of QoL. ${ }^{40}$ Although the effectiveness of CAB treatment has been confirmed, most patients with advanced prostate cancer unfortunately experience relapse, which has been named hormone refractory prostate cancer. To such relapsed prostate cancer after primary ADT failure, chemotherapy using docetaxel could be used as the standard treatment. On the other hand, other modalities of hormonal therapy using other anti-androgen agents, ${ }^{41}$ glucocorticoids, estrogens or ketoconazole could be used as the second or third hormonal therapy and have frequently been effective in so-called hormone refractory prostate cancer. Therefore, hormone refractory prostate cancer was shown to be not necessarily hormone-independent, and therefore it has been renamed castration-resistant prostate cancer (CRPC). The mechanisms of CRPC are thought to be as follows. First, these lesions are thought to have higher sensitivity of AR to androgen. AR signaling could be amplified by AR overexpression, AR mutations or changes in AR-interactive factors, such as cofactors. With such higher sensitivity of AR, even low levels androgen can induce AR activation. The second mechanism of CRPC is intraprostatic formation of androgens. As mentioned above, ${ }^{37,38}$ approximately $25 \%-40 \%$ of DHT remains in castrated prostate tissue in which enzymes that convert progesterone to androgen were shown to be overexpressed. This DHT is converted from precursor steroids, which are derived from the adrenal gland and peripheral tissues. This relatively low concentration of DHT may be sufficient to stimulate AR signaling via increased sensitivity of AR.

Given the several mechanisms of action of CRPC, ${ }^{42}$ the clinical development of novel agents is still ongoing. MDV3100 is a novel second generation anti-androgen. MDV3100 has greater binding affinity for AR to inhibit DNA binding of androgens to $\mathrm{AR}^{40}$ MDV3100 also inhibits nuclear translocation of androgens. In a phase $1 / 2$ multicenter study of 140 patients with CRPC, MDV3100 showed overall $\geqslant 50 \%$ PSA decrease in $56 \%$ of patients. ${ }^{44}$

Another target in CRPC is inhibition of androgen biosynthesis in prostatic cancer tissues. Inhibition of CYP17 is promising, because upregulation of CYP17 expression has been demonstrated in CRPC tissues. ${ }^{45}$ CYP17 catalyzes two essential reactions in androgen biosynthesis, $17 \alpha$-hydroxylase and C17, 20 lyase. Three novel selective inhibitors of CYP17 are currently under development. As abiraterone 
acetate inhibits both $17 \alpha$-hydroxylase and C17, 20 lyase, glucocorticoid replacement is necessary. Clinical trials to compare the effectiveness of abiraterone plus prednisone with those of prednisone plus placebo in CRPC patients previously treated with docetaxel are currently underway. Interim analysis demonstrated significant improvement of overall survival in patients treated with abiraterone plus prednisone. ${ }^{46,47}$ TAK700 is a more selective inhibitor of CYP17, because inhibition of C17, 20 lyase is more potent than that of $17 \alpha$-hydroxylase ${ }^{48}$ Thus, glucocorticoid replacement may be unnecessary or only minimal glucocorticoid replacement may be required in compared to patients treated with abiraterone. Phase $1 / 2$ studies of TAK-700 are currently underway. TOK-001 (previously VN/124-1) is also a selective inhibitor of CYP17. ${ }^{49}$ This compound could also downregulate AR expression. Other compounds targeting intact or truncated AR are also under investigation.

\section{ISSUES OF ADVERSE EFFECTS}

Several recent studies indicated that ADT increases the incidences of cardiovascular disease and bone fractures. Keating et al. ${ }^{50}$ demonstrated that GnRH agonist increased the risk of diabetes mellitus $(\mathrm{DM})$, coronary heart disease, myocardial infarction and sudden cardiac death, compared with the risks in patients without hormonal therapy. However, their paper had some limitations. First, this was not a randomized study. Therefore, patients receiving $\mathrm{GnRH}$ agonist may have been associated with higher levels of background factors contributing to DM or heart disease. For example, older men who are more likely to receive hormonal therapy are also likely to develop DM or coronary heart disease. Second, we cannot exclude the possibility that men receiving regular injection were more likely to be diagnosed with DM or coronary heart disease, because of the greater frequency of medical consultations. D'Amico et al. ${ }^{51}$ showed that a subset of men age 65 years or older who received 6 months of ADT demonstrated shorter intervals to fatal myocardial infarctions, compared with men in this age group who did not receive ADT. However, this paper was criticized by the authors of another paper recently published in the same journal. ${ }^{52}$ One major criticism was that D'Amico et al. did not show any difference in total number of fatal myocardial infarctions between groups. Their study was also criticized for its short treatment duration, shorter follow-up and the lack of information on cardiovascular disease (CVD) risk factors. Efstatiou et al. $^{52}$ described the first analysis using data from a large prospective study to directly address the potential relationship between $\mathrm{GnRH}$ agonists and cardiovascular mortality. In this study, patients with locally advanced prostate cancer who selected radiotherapy were randomly assigned to one of two arms. Patients in arm 1 received radiotherapy plus adjuvant hormonal therapy for 4.2 years on average. Those in arm 2 initially received only radiotherapy, and thereafter $64 \%$ of patients received salvage hormonal therapy after recurrence. Pre-treatment characteristics, including CVD risk factors, were similar between the two arms. Surprisingly, after 9 years, cardiovascular mortality rate for men treated with adjuvant hormonal therapy was $8.4 \%$, which was less than the rate of $11.4 \%$ for men without adjuvant hormonal therapy. However, patients with established CVD risk factors were significantly associated with greater cardiovascular mortality. Therefore, criticism of hormonal therapy should not be simplistic, but rather should focus on decreasing cardiovascular risk factors and managing CVD.

With regard to the adverse effects of hormonal therapy, data for the general population show that the incidence of ischemic heart disease is much lower in Japanese than in Westerners. For bone fractures, the incidence is much lower in Japanese than in Western populations. Based on these data, we expect that the adverse effects of hormonal therapy will be less in Japanese populations. Akaza et al. ${ }^{53}$ conducted the J-CaP study as a surveillance study of hormonal therapy in Japan. The data showed that the cardiovascular mortality rate in Japanese patients undergoing ADT was almost the same as that in the general population, as expected. Nevertheless, androgen deprivation could induce a variety of adverse effects even in Japan, because the adoption of a more Western life-style may increase the susceptibility to adverse effects by hormonal therapy. Therefore, efforts should be made to prevent or decrease such adverse effects as much as possible. Management strategies for ADT-associated morbidities are shown in Table 1. It is well known that bone mineral density decreased during long-term $\mathrm{ADT}$. Therefore, the fracture rate after $\mathrm{ADT}$ is not low. We performed a non-randomized prospective study to confirm the usefulness of bisphosphonate for improvement of the bone mineral density of patients receiving hormonal therapy. ${ }^{54}$ Whereas bone mineral densities of patients not receiving risedronate continued to decrease, those of patients receiving risedronate increased. Management of endocrine and metabolic dysfunctions, such as DM, is very important, although most urologists do not pay adequate attention to such nonsurgical issues. Androgen deficiency is now attracting attention as one of the causes of metabolic syndrome. Basaria et al. ${ }^{55}$ reported that hormonal therapy induces metabolic syndrome. They detected meta-

\section{Table 1 Management strategies for ADT-associated morbidities}

\begin{tabular}{ll}
\hline Complication & Management strategy \\
\hline Cardiovascular risk factors and disease & 1. Non-smoking \\
& 2. Consultation for diet and exercise \\
Osteoporosis and fractures & 3. Regular monitoring of serum lipid profiles \\
& $\begin{array}{l}\text { 1. Regular monitoring of BMD } \\
\text { Endocrine and metabolic dysfunction }\end{array}$ \\
2. Consultation for exercise, diet with adequate calcium and Vit D intake & 3. Bisphosphonates \\
Hot flash & 1. Consultation for nutrition, exercise, and weight control prior to ADT \\
Sexual dysfunction & 2. Regular monitoring of HbAlc and fasting blood sugar \\
& 1. Chlormadinone acetate \\
& 2. SSRI \\
1. PDE-5 inhibitors & 2. Cavernous injection of PGE-1 \\
& 3. Vacuum erection devices
\end{tabular}

Abbreviations: BMD, bone mineral density; ADT, androgen deprivation therapy; PDE-5, phosphodiesterase type-5; PGE-1, prostaglandin E-1; SSRI, selective serotonin reuptake inhibitors. 
bolic syndrome in more than $50 \%$ of men receiving long-term ADT. Therefore, we should carefully manage patients receiving hormonal therapy, and this is not as difficult as performing complicated surgery. The Endocrine Society Clinical Practice Guidelines will be helpful in preventing cardiovascular disease and DM. Furthermore, we should make our own clinical guidelines for urologists managing prostate cancer patients with hormonal therapy.

\section{ISSUES RELATED TO PATIENT SATISFACTION}

The Prostate Cancer Outcome Study yielded interesting results. ${ }^{56}$ In this study, patients' satisfaction was compared after each treatment; watchful waiting, primary androgen deprivation, radiotherapy and radical prostatectomy. Satisfaction was higher in men receiving primary ADT than in those managed by watchful waiting or radical prostatectomy. In addition, most patients indicated that they would make the same choice, if they had to select the treatment again. Thus, in patients requiring hormonal therapy, criticism of primary ADT should not be simplistic, but rather efforts should focus on decreasing its adverse effects.

\section{CONCLUSION}

Hormonal therapy has played an important role in the treatment of prostate cancer, since it was first introduced about 70 years ago by Huggins and Hodges. ${ }^{1}$ Recently, however, hormonal therapy has been the subject of frequent criticism. Some authors reported that it showed minimal effectiveness, while others suggested that it may reduce patients' QoL and induce adverse effects. Such reports should be evaluated very carefully. ${ }^{57}$ From Japanese experiences using hormonal therapy, we suspect that there may be ethnic differences in efficacy and adverse effects of hormonal therapy. Therefore, it is necessary to accumulate further clinical evidence concerning the efficacy and adverse effects of hormonal therapy. We should also strive to decrease its adverse effects, because life-style change may increase the susceptibility to adverse effects by hormonal therapy even in Japan. New hormonal compounds such as selective androgen receptor modulator capable of specifically targeting prostate cancer are expected to be developed.

\section{AUTHOR CONTRIBUTIONS}

MN contributed to the study design, analyzed data and wrote the manuscript. SU, YK and TF contributed to perform the studies. HA assisted with writing the manuscript.

\section{COMPETING FINANCIAL INTERESTS}

The authors declare no competing financial interests.

1 Huggins C, Hodges C. Studies on prostate cancer.1. The effect of castration, of estrogen and of androgen injection on serum phosphatases in metastatic carcinoma of the prostate. Cancer Res 1941; 1: 293-7.

2 Lu-Yao GL, Albertsen PC, Moore DF, Shih W, Lin Y et al. Survival following primary androgen deprivation therapy among men with localized prostate cancer. JAMA 2008; 300: 173-81.

3 Green HJ, Pakenham KI, Headley BC, Gardiner RA. Coping and health-related quality of life in men with prostate cancer randomly assigned to hormonalmedication of close monitoring. Psychooncology 2002; 11: 401-14.

4 Grant JD, Litwin MS, Lee SP, Steinberg ML, King CR. Does hormone therapy exacerbate the adverse effects of radiotherapy in men with prostate cancer? A quality of life study. J Urol 2011; 185: 1674-80.

5 Cancer Registration Committee of the Japanese Urological Association Clinicopathological statistics on registered prostate cancer patients in Japan: 2000 report from the Japanese Urological Association. Int J Urol 2005; 12: 46-61.

6 Maeda O. Option and indication for early stage prostate cancer. Jap J Cancer Chemother 2003; 30: 26-31. Japanese.
7 Fukagai T, Namiki TS, Carlile RG, Yoshida H, Namiki M. Comparison of clinical outcome after hormonal therapy for prostate cancer between Japanese and Caucasian men. BJU Int 2006; 97: 1190-3.

8 Akaza H, Homma Y, Usami M, Hirao Y, Tsushima T et al. Efficacy of primary hormonal therapy for localized or locally advanced prostate cancer: results of a 10-year followup. BJU Int 2006; 98: 573-9.

9 Egawa M, Misaki T, Imao T, Yokoyama O, Fuse $\mathrm{H}$ et al. Retrospective study on stage B prostate cancer in the Hokuriku District, Japan. Int J Urol 2004; 11: 304-9.

10 Kitagawa Y, Koshida K, Mizokami A, Komatsu K, Nakashima S et al. Pathological effects of neoadjuvant hormonal therapy help predict progression of prostate cancer after radical prostatectomy. Int J Urol 2003; 10: 377-82.

11 Schulman CC, Debruyne FM, Forster G, Selvaggi FP, Zlotta AR et al. 4-year-follow-up results of a European prospective randomized study on neoadjuvant hormonal therapy prior to radical prostatectomy in T2-3NOMO prostate cancer. Eur Uro/ 2000; 38: 70613.

12 Labrie F, Candas B, Gomez JL, Cusan L. Can combined androgen blockade provide long-term control or piossible cure of localized prostate cancer? Urology 2002; 60: $115-9$

13 Ueno S, Namiki M, Fukagai T, Ehara H, Usami M et al. Efficacy of primary hormonal therapy for patients with localized and locally advanced prostate cancer: a retrospective multicenter study. Int J Urol 2006; 13: 1494-500.

14 D'Amico AV, Whittington R, Malkowicz SB, Schultz D, Blank K et al. Biochemical outcome after radical prostatectomy, external beam radiation therapy, or interstitial radiation therapy for clinically localized prostate cancer. JAMA 1998; 280: 969-74.

15 Labrie F, Bélanger A, Luu-The V, Labrie C, Simard J et al. Gonadotropin-releasing hormone agonists in the treatment of prostate cancer. Endocrine Rev2005; 26: 36179.

16 Cooperberg MR, Grossfeld GD, Lubeck DP, Carroll PR. National practice patterns and time trends in androgen ablation for localized prostate cancer. J Natl Cancer Inst 2003; 95: 981-9.

17 Tanaka N, Hara H, Yamabe F, Takasugi K, Kataoka K et al. Investigation on prostate rebiopsy and high-sensitivity PSA of prostate cancer patients receiving endocrine therapy. Jap J Urol 2005; 96: 196. Japanese.

18 Akakura K, Ito H, Sato N. Intermittent androgen suppression for prostate cancer. Nippon Rinsho 2000; 58 (Suppl): 289-91. Japanese.

19 Mizokami A, Ueno S, Fukagai T, Ito K, Ehara $\mathrm{H}$ et al. Global update on defining and treating high-risk localizing prostate cancer with leuprolin: an Asian perspective. BJU Int 2007; 99 (Suppl): 6-9.

20 Kato T, Komiya A, Suzuki H, Imamoto T, Ueda T et al. Effect of androgen deprivation therapy on quality of life in Japanese men with prostate cancer. Int J Urol 2007; 14: 416-21.

21 Widmark A, Klepp O, Solberg A, Damber JE, Angelsen A et al. Endocrine treatment, with or without radiotherapy, in locally advanced prostate cancer (SPCG-7/SFUO-3): an open randomized phase III trial. Lancet 2009; 373: 301-8.

22 D'Amico AV, Whittington R, Malkowicz SB, Schultz D, Blank K et al. Biochemical outcome after radical prostatectomy, external beam radiation therapy, or interstitial radiation therapy for clinically localized prostate cancer. JAMA 1998; 280: 96974.

23 Bastian PJ, Gonzalgo ML, Aronson WJ, Terris MK, Kane CJ et al.Clinical and pathologic outcome after radical prostatectomy for prostate cancer patients with a preoperative Gleason sum of 8 to 10. Cancer 2006; 107: 1265-72.

24 Zietman AL, Shipley WU. Androgen deprivation and radiation therapy in prostate cancer: the evolving case for combination therapy. Int J Radiat Oncol Biol Phys 1997; 37: 245-6.

25 Joon DL, Hasegawa M, Sikes C, Khoo VS, Terry NH et al Supraadditive apoptotic response of R3327-G rat prostate tumors to androgen ablation and radiation. Int J Radiat Oncol Biol Phys 1997; 38: 1071-7.

26 Bolla $M$, Collette L, Blank L, Warde $P$, Dubois JB et al Long-term results with immediate androgen suppression and external irradiation in patients with locally advanced prostate cancer (an EORTC study): a phase III randomised trial. Lancet 2002; 360: 103-6.

27 D'Amico AV, Manola J, Loffredo M, Renshaw AA, DellaCroce A et al. 6-month androgen suppression plus radiation therapy vs radiation therapy alone for patients with clinically localized prostate cancer: a randomized controlled trial. JAMA 2004; 292: 821-7.

28 Pilepich MV, Winter K, John MJ, Mesic JB, Sause W et al. Phase III radiation therapy oncology group (RTOG) trial 86-10 of androgen deprivation adjuvant to definitive radiotherapy in locally advanced carcinoma of the prostate. Int J Radiat Oncol Biol Phys 2001; 50: 1243-52

29 Bolla M, de Reijke TM, van Tienhoven G, van den Bergh AC, Oddens J et al. Duration of androgen suppression in the treatment of prostate cancer. N Engl J Med 2009; 360: 2516-27.

30 Souhami L, Bae K, Pilepich M, Sandler H. Impact of the duration of adjuvant hormonal therapy in patients with locally advanced prostate cancer treated with radiotherapy: a secondary analysis of RTOG 85-31. J Clin Oncol 2009; 27: 2137-43.

31 Horwitz EM, Bae K, Hanks GE, Porter A, Grignon DJ et al.Ten-year follow-up of radiation therapy oncology group protocol 92-02: a phase III trial of the duration of elective androgen deprivation in locally advanced prostate cancer. J Clin Oncol2008; 26: 2497-504.

32 Stock RG, Cahlon O, Cesaretti JA, Kollmeier MA, Stone NN. Combined modality treatment in the management of high-risk prostate cancer. Int J Radiat Oncol Biol Phys 2004; 59: 1352-9. 
33 Nag S, Beyer D, Friedland J, Grimm P, Nath R. American Brachytherapy Society (ABS) recommendations for transperineal permanent brachytherapy of prostate cancer. Int $J$ Radiat Oncol Biol Phys 1999; 44: 789-99.

34 Messing EM, Manola J, Yao J. Immediate versus deferred androgen deprivation treatment in patients with node-positive prostate cancer after radical prostatectomy and pelvic lymphadenectomy. Lancet Oncol 2006; 7: 472-9.

35 Bittner N, Merrick GS, Wallner KE, Butler WM. Interstitial brachytherapy should be standard of care for treatment of high-risk prostate cancer. Oncology 2008; 22: 995-1017.

36 Dorff TB, Flaig TW, Tangen CM, Hussain MHA, Swanson GP et al. Adjuvant androgen deprivation for high-risk prostate cancer after radical prostatectomy: SWOG S9921 Study. J Clin Oncol 2011; 29: 2040-5.

37 Labrie F, Luu-The V, Liu SX, Labrie C, Simard J et al. The key role of 17ß-HSDs in sex steroid biology. Steroids 1997; 62: 148-58.

38 Mizokami A, Koh E, Fujita H, Maeda Y, Egawa M et al. The adrenal androgen, androstenediol, is present in prostate cancer tissue after androgen deprivation therapy and activates mutated androgen recetor. Cancer Res 2004; 64: 765-71.

39 Narimoto K, Mizokami A, Izumi K, Mihara S, Sawada K et al. Adrenal androgen levels as predictors of outcome in castration-resistant prostate cancer patients treated with combined androgen blockade using flutamide as a second-line anti-androgen. Int Urol 2010; 17: 337-45.

40 Akaza H, Hinotsu S, Usami M. Combined androgen blockade with bicalutamide for advanced prostate cancer: long-term follow-up of a phase 3, double-blind, randomized study for survival. Cancer 2009; 115: 3437-45.

41 Suzuki H, Okihara K, Miyake H. Alternative nonsteroidal antiandrogen therapy for advanced prostate cancer that relapsed after initial maximum androgen blockade. J Urol 2008; 180: 921-7.

42 Segura B, Ocana A, Tannock IF. Drug resistance in metastatic castration-resistant prostate cancer. Nat Rev Clin Oncol 2011; 8: 12-23.

43 Tran C, Ouk S, Clegg NJ, Chen Y, Watson PA et al. Development of a second-generation antiandrogen for treatment of advanced prostate cancer. Science 2009; 324: 787-90.

44 Scher HI, Beer TM, Higano CS, Anand A, Taplin ME et al. Antitumour activity of MDV3100 in castration-resistant prostate cancer: a phase 1-2 study. Lancet 2010; 375: 1437-46.

45 Stanbrough M, Bubley GJ, Ross K, Golub TR, Rubin MA et al. Increased expression of genes converting adrenal androgens to testosterone in androgen-independent prostate cancer. Cancer Res 2006; 66: 2815-25.
46 Attard G, Reid AH, A'Hern R, Parker C, Oommen NB et al. Selective inhibition of CYP17 with abiraterone acetate is highly active in the treatment of castrationresistant prostate cancer. J Clin Oncol 2009; 27: 3742-8.

47 Danila DC, Morris MJ, de Bono JS, Ryan CJ, Denmeade SR et al. Phase II multicenter study of abiraterone acetate plus prednisone in patients in patients with docetaxel treated castration-resistant prostate cancer. J Clin Oncol 2010; 28: 1496-501.

48 Dreicer R, Agus DB, MacVicar GR, MacLean D, Zhang T et al. Safety, pharmacokinetics, and efficacy of TAK-700 in castration-resistant metastatic prostate cancer: a phase I/II open label study. Genitourin Cancer Symp Proc 2010 89: abstract 103 .

49 Vasaitis T, Belosay A, Schayowitz A, Khandelwal A, Chopra P et al. Androgen receptor inactivation contributes to antitumor efficacy of $17 \alpha$-hydroxylase/17, 20-lyase inhibitor 3b-hydroxy-17-(1H-benzimidazole-1-yl)androsta-5, 16-diene in prostate cancer. Mol Cancer Ther 2008; 7: 2348-57.

50 Keating NL, O'Malley AJ, Smith MR. Diabetes and cardiovascular disease during androgen deprivation therapy for prostate cancer. J Clin Oncol 2006; 24: 4448-56.

51 D'Amico AV, Denham JW, Crook J, Chen MH, Goldhaber SZ et al. Influence of androgen suppression therapy for prostate cancer on the frequency and timing of fatal myocardial infarctions. J Clin Oncol 2007; 25: 2420-5.

52 Efstathiou JA, Bae K, Shipley WU, Hanks GE, Pilepich MV et al. Cardiovascular mortality after androgen deprivation therapy for locally advanced prostate cancer: RTOG85-01. J Clin Oncol 2009; 27: 92-9.

53 Akaza $\mathrm{H}$. Future prospects for luteinizing-hormone-releasing hormone analogues in prostate cancer treatment. Pharmacology 2010; 85: 110-20.

54 Izumi K, Mizokami A, Sugimoto K, Narimoto K, Miwa S et al. Risedronate recovers bone loss in patients with prostate cancer undergoing androgen-deprivation therapy. Urology 2009; 73: 1342-6.

55 Basaria S, Muller DC, Carducci MA, Egan J, Dobs AS. Hyperglycemia and insulin resistance in men with prostate carcinoma who receive androgen-deprivation therapy. Cancer 2006; 106: 581-9.

56 Hoffman RM, Hunt WC, Gilliland FD, Stephenson RA, Potosky AL. Patient satisfaction with treatment decisions for clinically localized prostate carcinoma: results from the Prostate Cancer Outcomes Study. Cancer 2003; 97:1653-62.

57 Namiki M, Mizokami A, Akaza H. Should patients with localized prostate cancer receive primary androgen deprivation therapy? Nat Clin Practi Urol 2009; 5: 648-9. 